\title{
Endoscopic Dacryocystorhinostomy Advantage over External Approach
}

\author{
Bijan Basak, ${ }^{1}$ Kaustuv Das Biswas, ${ }^{1}$ Subhradev Biswas, ${ }^{1}$ Ankit Choudhary ${ }^{1}$
}

\section{ABSTRACT}

\section{Introduction:}

Although external DCR was considered to be the Gold Standard treatment for NLD obstruction, endoscopic DCR appears to give comparable results, with the advantage of the absence of external facial scar and no disruption of the medial palpebral ligament or the angular facial vessels. This study aims to evaluate the outcome of endoscopic dacryocystorhinostomy (DCR) and compare with the outcome of external DCR, based on data available on literature search.

Materials and Methods:

In this prospective, longitudinal, interventional study, 67 cases of chronic dacryocystitis were operated endoscopically from January 2017 to December 2018. All patients were documented about detailed medical and operative history, thorough medical check up including ocular and ENT examination. Level of obstruction of nasolacrimal duct (NLD) was diagnosed by lacrimal syringing and probing.

Surgery was performed under local anaesthesia except in uncooperative patients where general anaesthesia was used. $0^{\circ} \& 30^{\circ}$ endoscopes were used in surgery. The surgical outcomes and complications were recorded, analyzed and compared to those of external DCR from available literature.

Results:

The overall success rate of endoscopic DCR was $94.7 \%$, which is closely comparable to external DCR.

\section{Conclusion:}

Endoscopic DCR is an effective and safe alternative to external DCR, with comparable results and better patient satisfaction.. Keywords:

Dacryocystitis; Dacryocystorhinostomy; endoscopes; Treatment Outcome

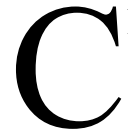

hronic dacryocystitis is defined as chronic inflammation of lacrimal sac due to stricture in nasolacrimal duct secondary to chronic inflammation mostly in nose. Patient complains of epiphora, sometimes associated with swelling of sac (mucocele) or even abscess due to superadded bacterial infections. Although attempt to correct NLD obstruction surgically dated back to $670 \mathrm{AD}$, it was not until 1904 , Addeo Toti described the classical external approach to create an alternative drainage pathway of lacrimal system into the nasal cavity, bypassing the NLD obstruction. ${ }^{1}$ The technique was modified by addition of suturing of nasal and lacrimal mucosal flaps by Dupuy-Dutemps

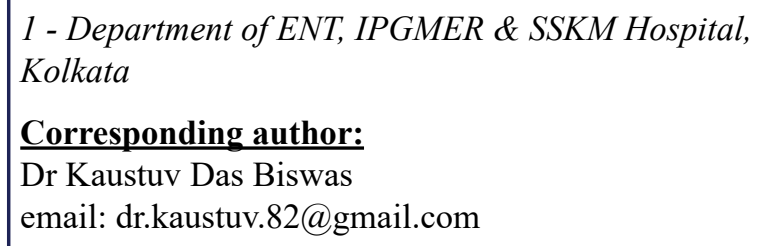

to form an epithelium lined fistula tract. ${ }^{2}$ The reported success rate of external DCR varies from $85-95 \%$ as per literature. ${ }^{3,4,5,6}$

Endonasal DCR was first described by Caldwell long back in 1893 , in which a portion of inferior turbinate was removed \& NLD was followed till the lacrimal sac. $^{7}$ It was later modified by West and Halle (1914) using microscope for better endonasal visualization. The interest in endonasal approach was renewed with the advent of rigid nasal endoscopes in the 1970s. Rice reported a cadaveric study demonstrating endoscopic intranasal DCR in 1988 followed by a review of 4 patients in $1990 .{ }^{8}$ The first clinical study on intranasal endoscopic DCR with the use of $30^{\circ}$ Storz Hopkins endoscope for visualization during surgery was published by Mc Donough and Meiring in $1989 .{ }^{9}$ Recently in 2002, Wormald PJ has described powered endoscopic DCR with full sac exposure \& primary mucosal anastomosis. ${ }^{10}$ Variations of endoscopic DCR like use of stents, 
LASER \& application of Mitomycin C have been tried in last decade, with variable but overall good results, comparable to that of external DCR.

Thus although external DCR was considered to be the Gold Standard treatment for NLD obstruction, ${ }^{11}$ but endoscopic DCR is gaining popularity among patients due to equal promising results, especially due to lack of external facial scar and no disruption of the medial palpebral ligament or the angular facial vessels. ${ }^{12}$

The present study aims to evaluate outcome and complications of endoscopic DCR and compare the outcome and complications of endoscopic DCR with those of external DCR as per available data from published literature.

\section{Materials and Methods}

The prospective, longitudinal, interventional study was conducted over a period of 24 months (January 2017 to December 2018). Institutional ethical committee clearance was obtained prior to commencement of the study. Patients attending the Ophthalmology \& ENT out-patient department (OPD) with complaint of epiphora during the period January 2017 to December 2018, were examined by ophthalmologist. Those cases who were diagnosed to have chronic dacryocystitis due to primary acquired NLD obstruction were considered. All patients underwent clinical examination including ENT examinations to note presence of deviated nasal septum (DNS) causing limited access to lacrimal sac area endonasally, nasal polyposis, hypertrophied turbinates/ concha bullosa, atrophic rhinitis, tumours, sinus infections. Infections were controlled preoperatively and DNS, polyps, concha bullosa were dealt with per-operatively. Tumour causing NLD obstruction were excluded from the study.

Ophthalmological examination was key to diagnose the cases with syringing of NLD and probing. Eyelids were examined for ectropion, lid laxity or entropion. Lacrimal puncta were examined for normal location and size.

All symptomatic cases of epiphora due to chronic dacryocystitis caused by primary acquired NLD obstruction including patients with mucocele/ lacrimal abscess, who opted for surgical treatment and those who were found to be medically fit after investigations were included in the study. Patients with history of prior external DCR operation were also included.

Children younger than 15 years of age, patients with canalicular and/or punctual obstruction, ectropion, entropion or lower lid laxity, tumour of lacrimal sac or nose causing NLD obstruction or patients with severe co-morbidities leading them medically unfit were excluded from the study.

A total of 67 patients were included in our present study, of whom 42 were female and 25 patients were male, with the condition being bilateral in 14 cases. So total 81 cases of NLD system were operated. Follow up of the cases post-operatively were scheduled at weekly intervals for first 1 month, then at 3 month and 6 month intervals. Patency of NLD was checked by sac syringing and was combined with endoscopic examination of the stoma endonasally. Outcomes were classified as complete cure, partial cure or no improvement based on symptomatic relief post-operatively.

Endoscopic DCR was performed under local anaesthesia in majority of the cases (76 cases i.e. 93.83\%) except 5 cases (i.e. 6.17\%) which were operated under general anaesthesia due to reduced compliance of the patient under local anaesthesia. $0^{\circ} \&$ $30^{\circ}$ rigid nasal Hopkins Rod endoscopes were used in the endonasal surgery for visualization. Standard steps of endonasal incision, flap elevation, enlargement of bony ostium, full length opening of the lacrimal sac and approximation of nasal mucosa with that of lacrimal sac mucosa was performed. No sutures or silastic tubes or sheets were used in any of our cases. Per-operatively lacrimal sac syringing was done with normal saline and free flow was noted endoscopically.

Post-operatively patients were advised to instill antibiotic steroid eye drop. All the patients were discharged on first post-operative day and were called for regular follow-up, where nasal suction and syringing of lacimal sac were done once a week for first 1 month and then at 3 monthly and 6monthly intervals postoperatively. Nasal endoscopy was done after 1 month, to check patency of the stoma endonasally and to simultaneously remove any crust and granulation if 
present.

\section{Results}

A total of 81 lacrimal systems (hereinafter referred to as cases) of 67 patients were operated from January 2017 to December 2018, of which, 14 patients had bilateral disease. Of the 67 patients, 42 patients were female $(62.7 \%)$ and 25 were male $(37.3 \%)$.

The minimum age of patient treated by endoscopic DCR was 21 years whereas the maximum age was 64 years with a mean age of 35.8 years as per patients included in our study. Most of the cases were unilateral (79\%) whereas 14 cases were bilateral (21\%).

In our study, 76 cases (94\%) were fresh case without any history of prior operation and 5 cases $(6 \%)$ were recurrence cases with prior history of failed external DCR operations. Of the primary cases, majority were idiopathic in origin ( 48 cases i.e. 59\% ) followed by infectious aetiology resulting in pyocele (16 cases i.e. $20 \%$ ) and mucocele in 12 cases (15\%).

Majority of the cases presented with epiphora (65 cases i.e. $80 \%$ ), 12 cases(i.e. 15\%) had mucocele associated with epiphora. Active infection was present in 10 cases (i.e. 12\%) which was controlled with pre-operative antibiotic therapy and fistula with mucopurulent discharge was present in 5 cases $(6 \%)$.

DNS was present in 15 cases (18.5\%) \& hypertrophied middle turbinate/ concha bullosa was present in $5(6 \%)$ cases, which were surgically corrected simultaneously.

The average operative time for endoscopic DCR was estimated to be $45 \pm 9$ minutes in our study. Complications included excessive intraoperative bleeding in $5 \%$ case (i.e. 4 cases), which were controlled by local adrenaline packing and blood pressure control. None of the cases were abandoned due to bleeding. Serious complications like orbital injury and CSF rhinorrhoea has not occurred in any of the cases in our study.

Average duration of follow-up of the cases was 6.4 months in the present study. The primary operation was successful in 61 patients with complete cure of symptoms (i.e. 91\%) at the end of 1 month follow-up. In 3 cases $(3.7 \%)$ developed oedematous granulation tissue blocking the ostium, causing obstruction, which were removed endoscopically and on follow-up, these patients became symptom free. On routine follow up, at 3 months interval, 2 patients (3\%) needed trimming of hypertrophied mucosa overlying the ostium and another 4 patients $(6 \%)$ patients had granulations at the end of the ostium, which were excised endoscopically.

Eventually on 6 months follow up these patients became symptom free, thus achieved complete cure of symptoms. On 6 months follow-up 2 patients (3\%) developed failure due to re-stenosis of the stoma and were resorted to external dacryocystectomy to achieve symptom relief. 1 patient ( $2 \%$ ) was lost on follow up.

Thus after revision surgery, the success rate was 94.7\%. Endoscopic examinations in first few weeks post-operatively showed gradual decrease in ostium size, which was stabilized between $4-6$ weeks on completion of healing process. Minimal change of ostium was noted thereafter on long term follow up.

\section{Discussion}

External DCR, although considered gold standard \& was widely practised for NLD obstruction, but endoscopic DCR is rapidly gaining popularity as an alternative to treat primary NLD obstruction with comparable results. Both the procedures have some benefits and disadvantages.

External DCR has the advantage of direct visualization of lacrimal sac, surrounding structures, intra sac abnormalities as compared to endoscopic approach, ${ }^{12}$ and lack of need of expensive instruments and technical feasibility to suture flaps between lacrimal sac and nasal mucosa, thereby increasing the success rate of the procedure, ${ }^{13}$ but external approach has the disadvantages of cutaneous scar, chances of injury to medial canthal structures and disruption of physiological lacrimal pump mechanism. ${ }^{14}$

On the other hand, endoscopic DCR avoids external scar, endonasal visualization and assessment can be done immediately with correction of pathology including endonasal pathologies (DNS, turbinate hypertrophy etc.) avoids failure and in extreme cases it can still be converted to external procedure especially in cases with lacrimal sac tumors. ${ }^{15}$ Disadvantages of 


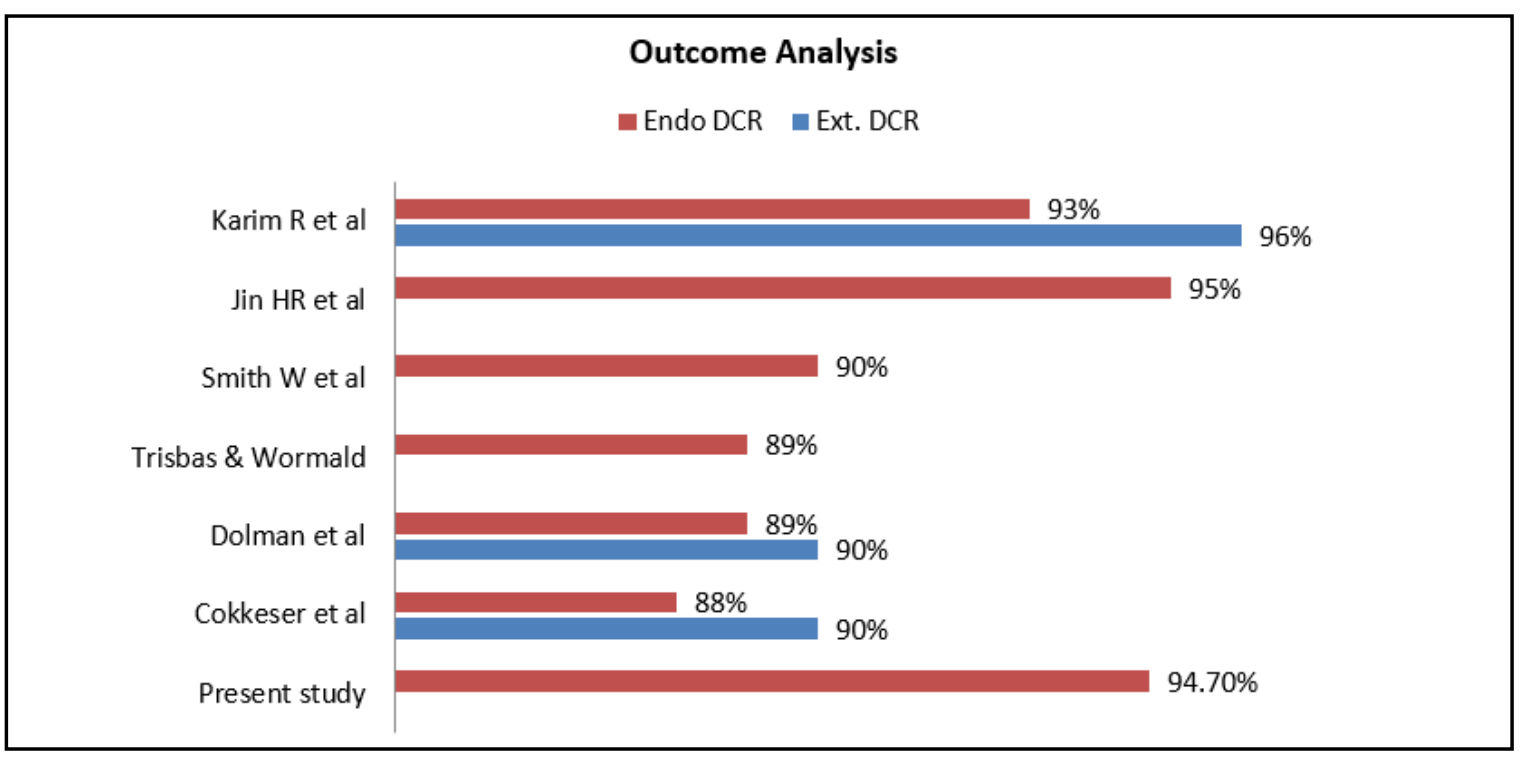

Fig. 1: Comparison of outcomes of DCR of different studies

endoscopic DCR include need for costly instruments, steep learning curve and difficulty in suturing nasal and lacrimal flaps. With improved instrumentation and technical modifications, success rates of endoscopic DCR appears to be comparable to the 'Gold Standard' external DCR procedure with success rate ranging from $78 \%$ to $97 \%$ in various studies. ${ }^{16,17}$

In our study, 42 patients were female and 25 patients were male with a female: male ratio of $1.68: 1$, thus showing NLD obstruction is more common in females, which corroborates with available literature. ${ }^{18,19,20}$ It was noted that epiphora was the commonest presenting symptom in $80 \%$ cases in our study. Similar observations were made in previous studies. . $11,21,22^{2}$

In a study performed in Bangladesh, the duration of surgery in endoscopic DCR was $59.7 \pm 8.8$ minutes which was significantly higher than that for external DCR group which was $54.3 \pm 5.6$ minutes. ${ }^{12}$ Muscatello et al reported in their study that mean time for endonasal endoscopic DCR was 30 minutes, ranging from 15110 minutes and time progressively decreased with increasing surgical experience. ${ }^{23}$ In another study by Hartikainen et al, it was concluded that average duration for endoscopic DCR was 38 minutes and 78 minutes for external DCR. ${ }^{24}$ The average operative time for endoscopic DCR was estimated to be $45 \pm 9$ minutes in our study, which is similar to that of available literature. In our study, we found that operative times are closely related to the surgical experience of the surgeon and intraoperative bleeding.

Numerous studies have compared endoscopic DCR with traditional external DCR regarding outcome. (Fig. 1) Cokkeser et al found comparable success rates between external and Endo-DCR $(90 \%$ versus $88 \%) .{ }^{25}$ Another study comparing external DCR and non-laser endonasal DCR, found both procedures to have equivalent success rates $(90 \%$ versus $89 \%){ }^{26}$ The author also noted that the endonasal technique was more acceptable in patients who suffered bilateral NLD obstruction and in whom the other side was operated by external approach.

Thus while both the procedures have equivalent success rate as well as complication rates, as per the study by Gauba, comparing endonasal DCR to external DCR, ${ }^{27}$ patient satisfaction was noted to be slightly higher with endonasal DCR surgery. Absence of skin scar and quicker recovery time with lesser follow up appointments ( no need for suture removal) led to significant higher patient satisfaction for those who underwent endoscopic DCR. ${ }^{27}$ Furthermore it was noted that time to relief of symptoms after the surgery was statistically significantly shorter in endoscopic DCR 
compare to external DCR (1.7 vs. 3.7 weeks). ${ }^{28}$

Both surgical procedures (endoscopic and external DCR) have minimal rate of complications like hemorrhage, as also noted in our study with only $4 \%$ cases demonstrated excessive intra-operative bleeding but all were controlled; none of the cases were abandoned due to haemorrhage. Complications of endonasal DCR are low but can include re-stenosis of the opening, bleeding from the nasal cavity, orbital injury or canaliculi erosion. ${ }^{29}$ Tsirbas and Wormald described a technique in endoscopic DCR to fully expose the lacrimal sac and marsupialize it into the lateral nasal wall with the nasal and lacrimal mucosa in apposition. They achieved high long-term success rates with this approach at $89 \%$, which is comparable to that of external DCR. ${ }^{30}$

Although endonasal DCR has high success rate but chances of failure may be because of certain factors like anatomical variation in nasal cavity, cicatricial closure of the ostium, ${ }^{31-33}$ adhesion between the ostium and the middle turbinate ${ }^{34}$ and granuloma formation within the ostium. ${ }^{31}$ It is to be noted that all of these complications are amenable to revision surgeries. Post-operative stringent follow-up leads improved outcome in endoscopic DCR. Rare but potentially dangerous complications like orbital and subcutaneous emphysema, retrobulbar hemorrhage, medial rectus paresis, and orbital fat herniation can occur in both forms of DCR surgery, although very few of these are reported in literature ${ }^{35-37}$ Fortunately none of these occurred in our present study.

Surgical successs for DCR surgery encompassed both anatomical patency and symptom relief. In our study objective endonasal stoma patency as well as subjective symptomatic relief of the patients both were considered, indicating overall success rate of $94.7 \%$, which is closely comparable to external DCR, the so called 'Gold standard' procedure for NLD obstruction.

\section{Conclusion}

Endoscopic DCR has revolutionized the treatment of NLD obstruction, with outcome comparable to external DCR. Thus the present study upholds endonasal DCR is an effective and safe alternative to external DCR with higher patient satisfaction \& distinct advantages as mentioned in this study.

\section{References}

1. Toti A. Nuovo metodo conservatore dicura radical delle suppurazioni croniche del sacco lacrimale (dacriocistorinostomia). Clin Mod Firenze. 1904; 10:385-7

2. Dupuy-Dutemps MM, Bourguet ET. Note preliminaire sur un proded de dacrocystorhinostomie. Ann D Ocul. (Paris) 1920; 157:1445-7

3. Tarbet KJ, Custer PL. External dacryocystorhinostomy. Surgical success, patient satisfaction, and economic cost. Ophthalmol. 1995; 102:1065-70

4. Mekonnen W, Adamu Y. Outcome of external dacryocystorhinostomy in Ethiopian patients. Ethiop Med J. 2009; 47:221-6

5. Fayers T, Laverde T, Tay E, Olver JM. Lacrimal surgery success after external dacryocystorhinostomy: Functional and anatomical results using strict outcome criteria. Ophthal Plast Reconstr Surg. 2009; 25:472-5

6. Warren JF, Seiff SR, Kavanagh MC. Long-term results of external dacryocystorhinostomy. Ophthalmic Surg Lasers Imaging 2005; 36:446-50

7. Caldwell GW. Two new operations for obstruction of the nasal duct with preservation of the canaliculi and with an incidental description of a new lacrimal probe. Am J Ophthalmol. 1893; 10:189-93

8. Rice DH. Endoscopic intranasal dacryocystorhinostomy: Results in 4 patients. Arch Otolaryngol.1990; 116:1061

9. Mc Donough M, Meiring JH. Endoscopic transnasal dacryocystorhinostomy. J Laryngol and Otol. 1989; 103:585-7

10. Wormald PJ. Powered endoscopic dacryocystorhinostomy. Laryngoscope 2002; 112(1):69-72

11. Karim R, Ghabrial R, Lynch TF, Tang B. A comparison of external and endoscopic endonasal dacryocystorhinostomy for acquired nasolacrimal duct obstruction. Clin Ophthalmol. 2011; 5:979-89

12. Khan MK, Hossain MA, Hossain MJ, Al-Masud A, Rahman MZ. Comparative study of external and endoscopic endonasal dacryocystorhinostomy for the treatment of chronic dacryocystitis. JAFMC Bangladesh 2011; 7:15-7

13. Amadi AJ. Endoscopic DCR vs External DCR: What's Best in the Acute Setting? J Ophthalmic Vis Res. 2017; 12(3): 251-3

14. Shun-Shin GA, Thurairajan G. External dacryocystorhinostomyan end of an era? Br J Ophthalmol. 1997; 81:716-7

15. Zhou W, Zhou M, Li Z, Wang T. Endoscopic intranasal dacryocystorhinostomy in forty-five patients. Chin Med J (Engl). 1996; 109:747-8

16. Smith W, Merkonidis C, Draper M, Yung M. Endoscopic dacryocystorhinostomy in warfarinized patients. Am J 
Otolaryngol. 2006; 27:327-9

17. Jin HR, Yeon JY, Choi MY. Endoscopic dacryocystorhinostomy: Creation of a large marsupialized lacrimal sac. J Korean Med Sci. 2006; 21:719-23

18. Hurwitz JJ, Rutherford S. Computerized survey of lacrimal surgery patients. Ophthalmology 1986; 93:14-9

19. Tan NC, Rajapaksa SP, Gaynor J, Nair SB. Mechanical endonasal dacryocystorhinostomy-a reproducible technique. Rhinology 2009; 47:310-5

20. Moras K, Bhat M, Shreyas CS, Mendonca N, Pinto G. External dacryocystorhinostomy versus endoscopic dacryocystorhinostomy: A comparison. J Clin Diagn Res. 2011; 5:182-6

21. Nichlani SS, Jagade MV, Ganeshan A. A comparative study between endoscopic and external approach dacryocystorhinostomy. Bombay Hosp J. 2010; 52:189-96

22. Aslam S, Awan AH, Tayyab M. Endoscopic dacryocystorhinostomy: A Pakistani experience. Pak J Ophthalmol. 2010; 26:2-6

23. Muscatello L, Giudice M, Spriano G, Tondini L. Endoscopic dacryocystorhinostomy: Personal experience. Acta Otorhinolaryngol Ital. 2005; 25:209-13

24. Hartikainen J, Antila J, Varpula M, Puukka P, Sepp H, Grénman R. Prospective randomized comparison of endonasal endoscopic dacryocystorhinostomy and external dacryocystorhinostomy. Laryngoscope 1998; 108:1861-6

25. Cokkeser Y, Evereklioglu C, Er H. Comparative external versus endoscopic dacryocystorhinostomy: results in 115 patients (130 eyes). Otolaryngol Head and Neck Surg. 2000;123(4):488-91

26. Dolman PJ. Comparison of external dacryocystorhinostomy with non laser endonasal dacryocystorhinostomy. Ophthalmol. 2003; 110(1):78-84

27. Gauba V. External versus endonasal dacryocystorhinostomy in a specialized lacrimal surgery center. Saudi J Ophthalmol. 2014; $28: 36-9$

28. Pei-Yuan S. Comparison of endoscopic and external dacryocystorhinostomy for treatment of primary acquired nasolacrimal duct obstruction. Taiwan J Ophthalmol. 2008; 8(1):19-23

29. Saha R, Kumar P, Maurya RP, Singh VP, Singh MK, Kumar R. Endoscopic Vs External Approach DCR: A comparative Analysis. Ind J Cl and Expmntl Ophthalmol. 2015; 1(3):134-42

30. Tsirbas A, Wormald PJ. Mechanical endonasal dacryocystorhinostomy with mucosal flaps. Br J Ophthalmol. 2003; 87:43-7

31. Woog JJ, Metson R, Puliafito CA. Holmium YAG endo-nasal laser dacryocystorhinostomy. Am J Ophthalmol. 1993; 116:110

32. Camara JG, Bengzon AU, Henson RD. The safety and efficacy of mitomycin $\mathrm{C}$ in endonasal endoscopic laser-assisted dacryocystorhinostomy. Ophthal Plast Reconstr Surg. 2000; $16: 114-8$

33. Hausler R, Caversaccio M. Microsurgical endonasal dacryocystorhinostomy with long term insertion of bicanilicular silicon tubes. Arch Otolaryngol Head Neck Surg. 1998; 124: 188-91

34. Neuhaus RW, Baylis HI. Cerebrospinal fluid leakage after dacryocystorhinostomy. Ophthalmol. 1983; 90:1091-5.

35. Wesley RE, Bond JB. Intranasal procedures for successful lacrimal surgery. Ophthal Plast Reconstr Surg. 1986; 2:153-7

36. Hurwitz JJ, Eplett CJ, Fliss D, Freeman JL. Orbital hemorrhage during dacryocystorhinostomy. Can J Ophthalmol. 1992; 27:139-42

37. Jae Wook Yong, $\mathrm{Ha} \mathrm{Na}$ Oh. Success rate and complication of endonasal dacrocystorhinostomy with unciformectomy. Graefes Arch Clin Exp Ophthalmol. 2012; 250:1509-13. 